\title{
Development of a Generic Aircraft aintenance Management Database for Zambia Air Force
}

\author{
Joana Bwalya Chemba ${ }^{1 *}$ and Isaac N. Simate ${ }^{2}$ \\ ${ }^{1 \& 2}$ Department of Agricultural Engineering, School of Engineering, University of Zambia, Lusaka, Zambia \\ *Correspondence
}

\begin{abstract}
The aviation industry is one of the most strictly regulated industries in the world. National and international aviation regulating authorities stipulate a number of requirements for both civil and military aviation establishments. One of the areas these regulations apply to is aircraft maintenance information management. With the evident technological advancement, the aviation regulators allow the use of electronic databases in aircraft maintenance. This study was aimed at developing a generic aircraft maintenance management database for Zambia Air Force (ZAF). The results of the baseline study conducted at one aircraft maintenance unit showed that the majority $(86 \%)$ of respondents use a paper based aircraft maintenance information database. According to the respondents, the lack of skills, inadequate computers and security are the reasons for the continued use of a paper-based system. Additionally, the main challenges faced using this information database based on the results are time-consuming, misplaced documents and some information is not documented. A database was developed using Microsoft Access based on the reviewed aviation regulations with regard to maintenance information records. The database has attributes of managing aircraft information, personnel information as well as material, spares and equipment information. Furthermore, the implementation results show that the database can address the challenges currently faced with the paper based system and aid maintenance managers with (1) decision making (2) maintenance planning and execution (3) spares inventory management.
\end{abstract}

Key words: Aircraft Maintenance, Maintenance Regulations, Maintenance Management Database, Microsoft Access Database, Development of Database

\section{INTRODUCTION}

$\mathrm{M}$ aintenance management is a complex partnership between the people directly or indirectly involved in maintenance, the processes and strategies to direct people's actions, the physical asset being maintained and finally the Computerised Maintenance Management Systems - the main link between the "people", "processes and strategies" and "asset" (Gouws \& Trevelyan, 2008). The field of aviation maintenance has seen a significant change in the documentation requirements for aircraft and related parts. Today, there is a mixture of various database programs offering a combination of the data research required to conduct proper maintenance, inspections, and data recording (logbook entries, Air Data compliance history, length of component time in service, and so forth) desired to improve the efficiency of the technician (FAA, 2018).
Effective management of maintenance is nearly not possible without computerization. Also implementing these with a good success rate needs a major program for change management over time (Giridharan et al, 2020). Aircraft operators are pushing for faster troubleshooting, automated aircraft inspection to reduce downtime; better task planning, and optimized parts management (Uniting Aviation, ICAO, 2019).

In the early 1980's, large corporations found their progress seriously hampered by paper-based systems. Hence, they tried to develop solutions internally, as no commercial systems were available (Johnson \& Millians, 2000). Jorgensen and Fuller (1993) identified existing problems with paper technical manuals by stating that they are unnecessarily costly to produce and manage as additional personnel and facilities are required for physical control of information, which could be more efficiently handled. The two researchers also noted that the paper-based system was of such poor usability (e.g., in finding specific information) and comprehensibility (e.g., in complex fault isolation processes), as to seriously slow the maintenance process, increase false part-removal rates, and significantly increase training time. One emerging solution to these problems was the Integrated Electronic Technical Manual (IETM). Measurable field results, from Navy, Air Force and Army, showed not only that the great majority of technicians found the IETM approaches desirable, but that maintenance performance was significantly improved.

The TM digitization movement initially was driven by the fact that printing, distributing, maintaining, and storing paper technical publications was consuming increasing resources and using large amounts of infrastructure. The digitization effort was also spurred by research that indicated that digital information systems were not only less costly but more effective and efficient to use in their primary role of supporting system operations and maintenance than paperbased products (Belcher \& Neisler, 2000). The presentation of maintenance information to shipboard and flight line technicians was made possible, with the advent of the IETM (Jorgensen \& Fuller, 2006).

An Aircraft is a system that requires high reliability levels throughout its flights. Preventive maintenance procedures are applied to maintain this reliability at an optimum level (Kiyak, 2011). Optimal aircraft availability is a common objective of both military aircraft divisions and commercial airlines 
although having different organisational goals. To achieve this objective, efficient preventive maintenance measures are put into practice. Different maintenance approaches are adopted by different organisations and constantly revised to incorporate modern and efficient maintenance techniques. Important issues in maintenance management range from various optimization models, maintenance techniques, scheduling, and information systems, etc. (Garg \& Deshmukh, 2015).

Reducing cost, minimizing downtime and ensuring reliability levels, are central objectives in any sector of industrial activity, and maintenance is observed as an important service. To achieve these goals, decision support systems should be available, optimizing the exploration and maintenance plans and ensuring that companies are meeting their goals. For this reason, it is necessary to collect reliable and consistent data. Its analysis and treatment will allow the computation of reliability values, to validate Failure Mode, Effects and Criticality Analysis (FMECA) and re-plan production and maintenance. Duartea et al (2013) focused on the need for the existence of a maintenance database and proposed an architecture for connecting the multiple vertices that generate information to feed the database. The architecture presented should drive developments in building a platform that ensures data to be collected and processed and to link the Original Equipment Manufacturer (OEM), customers and maintenance providers, as shareholders of maintenance database and with the responsibility in feeding it with data during different phases of the product life cycle. The existence of a maintenance database provides reliable information for analysis and will contribute significantly to plan the installation phase of equipment and its use.

According to Wiksten and Johansson (2006) even if a system is maintained, deviations will occur; these deviations must be considered separately since they tend to occur randomly at times and these are the unscheduled maintenance tasks. The two scholars also emphasise the importance of recording and archiving the scheduled and unscheduled maintenance tasks. There are already developed software available on the market. The software takes care of probability calculations of failures and spare part optimization. However, the burden of license fees is too high for small and medium maintenance organisations to justify the use of these software programs. Many of these programs offer a combination of the data research, such as Airworthiness Directives (ADs), Service Bulletins etc. required in conducting proper maintenance, inspections, and data recording (logbook entries, AD compliance history, length of component time in service, and so forth) desired to improve the efficiency of the technician.

There is a basic record form of aircraft servicing in ZAF. In it are details of all servicing operations on the aircraft and its phased components. The form is of great importance because its compiles all instructions which define individual responsibilities for making the necessary entries. Those concerned are to ensure that instructions are complied. A record is kept of types of aircraft on which tradesmen are competent to undertake aircraft servicing and the dates of authorization and re-examination. It is mandatory for the upkeep of equipment records to be at all formations mainly for two reasons; statistical purpose and equipment inspections and servicing monitoring (ZAF AP, 2004).

On maintenance records, Zambia Civil Aviation Authority (ZCAA) gives instructions that each person who maintains, performs preventive maintenance, rebuilds, or modifies an aircraft or life limited parts shall, when the work is performed satisfactorily, make an entry in the maintenance record of that equipment. The relevant information includes total time in service, appropriate details of modifications and repairs, total time since last overhaul, completion date of works performed personnel doing the works etc. (ZCAA, 2021).

Federal Aviation Administration regulations (FAA, 2018) require the technician to make appropriate entries of maintenance actions or inspection results in the aircraft maintenance record. Whenever maintenance, preventive maintenance, rebuilding, or alteration work occurs on an aircraft, airframe, aircraft engine, propeller, appliance, or component part, a maintenance record entry must be created. Temporary records are records that must be kept by the owner until the work is repeated, superseded, or 1 year has elapsed since the work was performed. The owner must retain permanent records during the time he or she operates the aircraft.

In the research conducted by Backes et al (2017), it was discovered that throughout the lifecycle of a commercial airplane, repairs are incorporated, components are replaced and maintenance tasks are accomplished every day, each of those activities generate records that need to be kept and reconciled. This process is done mostly with paper documents and is very costly and difficult for the industry to manage. The implementation of electronic records can help eliminate usage of up to 30,000 sheets of paper a year per aircraft, while increasing control and efficiency in the airline daily operation. Such approach would optimize processes reducing labor hours in the Maintenance Records Quality Assurance process by $50 \%$ or more. Other savings include reduction delays in the airplane transition and duplication of maintenance activities due to missing records.

\section{METHODOLOGY}

A qualitative approach was adopted to achieve the objective of this study. Paper questionnaires were used as the method of primary data collection. A framework of themes and closed and open-ended questions were established based on the study objective. Simple random sampling was the sampling method used. The participants comprised of top management, maintenance planners and technicians from both mechanical and avionics trades. This enhanced the data validity and reliability.

A survey was conducted focusing on aircraft maintenance personnel from a transport-aircraft maintenance unit in 
Lusaka. The unit, at the time of research, had 146 personnel belonging to two main trades, namely mechanical and avionics. Secondary data was collected through review of ZAF and other regulating authorities' aircraft maintenance regulations and standards to derive the most relevant information required for the development of the maintenance database. The database development model adopted in this research was the incremental model.

Primary data was collected through self-distributed semistructured questionnaires. Sixty (60) questionnaires were randomly distributed among aircraft maintenance personnel, out of which forty-four (44) were answered and submitted back. The questionnaires were designed with open and closedend questions aimed at finding out the experience of personnel in aircraft maintenance and their ICT knowledge to assess the requirements of the database implementation. Data collected from the questionnaires was analysed using statistical techniques and presented as percentages in charts and tables whereas content analysis method was used to categorise the secondary data.

\section{RESULTS}

\section{A. Respondents' Profiles}

Forty-four (44) questionnaires were answered and collected representing a response rate of $73 \%$ of the sixty (60) that were randomly distributed among aircraft maintenance personnel. Table 1 and Table 2 show the respondents profile by management level and the work experience respectively, at the aircraft maintenance unit.

Table 1. Respondents profile by management level

\begin{tabular}{|c|c|c|}
\hline Management Level & Frequency & \% \\
\hline Department Managers & 4 & 9 \\
\hline Unit managers & 8 & 18 \\
\hline Mechanical Technicians & 13 & 30 \\
\hline Avionics Technicians & 19 & 43 \\
\hline Total & $\mathbf{4 4}$ & $\mathbf{1 0 0}$ \\
\hline
\end{tabular}

Table 2. Respondents work experience

\begin{tabular}{|c|c|c|}
\hline $\begin{array}{c}\text { EXPERIENCE AT } \\
\text { MAINTENANCE UNIT }\end{array}$ & Frequency & $\%$ \\
\hline $0-5$ years & 2 & 5 \\
\hline 5-10 years & 7 & 16 \\
\hline 10-15 years & 7 & 16 \\
\hline 15-20 years & 18 & 41 \\
\hline More than 20years & 10 & 23 \\
\hline Total & $\mathbf{4 4}$ & $\mathbf{1 0 0}$ \\
\hline
\end{tabular}

The results show that $64 \%$ of personnel had more than fifteen (15) years of experience in aircraft maintenance. The results also show that the respondents with between 5-10 years and those between 10-15 years had the same percentage of $16 \%$ each. Only $5 \%$ of the personnel had less than five (5) years of experience as indicated in Table 2.

\section{B. Maintenance Information Accessibility}

Figure 1 shows that $86 \%$ of participants in the survey use paper or books to access aircraft maintenance information while $14 \%$ use electronic databases.

\section{Means of accessing maintenance information}

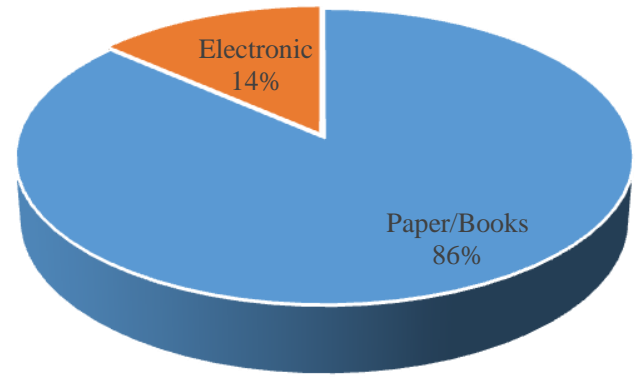

Figure 1: Type of Information Platform

The participants were asked to give reasons for non-use of an electronic maintenance system. The findings shown in table 3 of the distribution of the responses analysis depict that $84 \%$ and $75 \%$ of respondents attributed the lack of skills and inadequate computers to be the reasons respectively. Only $11 \%$ of the respondents considered security reasons and $5 \%$ mentioned the migration from paper to electronic system as a cumbersome process as one of the reasons.

Table 3: Non-use of Electronic System

\begin{tabular}{|c|c|c|}
\hline $\begin{array}{c}\text { Reasons for Non-use } \\
\text { of Electronic System }\end{array}$ & $\begin{array}{c}\text { Percentage (\%) } \\
\text { Response }\end{array}$ & Ranking \\
\hline Lack of skills & 84 & 1 \\
\hline Inadequate computers & 75 & 2 \\
\hline Security Reasons & 11 & 3 \\
\hline Other reasons & 5 & 4 \\
\hline
\end{tabular}

A total of $77 \%$ respondents further indicated having challenges in accessing aircraft maintenance information as shown in figure 2 below. 
Do you face challnges accessing aircraft maintenance information?

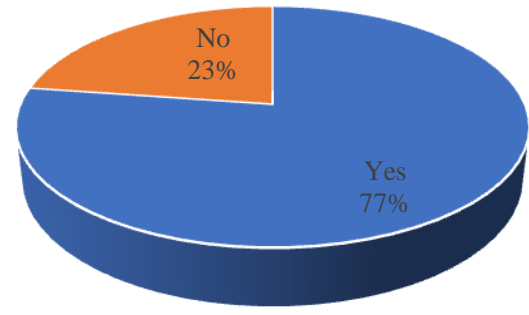

- Yes - No

Figure 2: Maintenance Information Accessibility

The study was also aimed at discovering the challenges faced with the current aircraft maintenance system, the results are shown in table 4 . Time-consuming was indicated by a total of $53 \%$ of the respondents as one of the challenges faced while $47 \%$ said documents get misplaced. Other responses were that some information is not documented (41\% responses) or if documented, is sometimes incorrect (15\% responses).

Table 4: Challenges Faced with current main system

\begin{tabular}{|c|c|c|}
\hline Challenges Faced & $\begin{array}{c}\text { Percentage (\%) } \\
\text { Response }\end{array}$ & Ranking \\
\hline Time-consuming & 53 & 1 \\
\hline Misplaced documents & 47 & 2 \\
\hline $\begin{array}{c}\text { Some Information not } \\
\text { documented }\end{array}$ & 41 & 3 \\
\hline Other & 15 & 4 \\
\hline
\end{tabular}

\section{Information Communication Technology (ICT) Literacy}

A study was conducted to find out the level of ICT among the aircraft maintenance personnel. The results are shown in figure 3 and illustrate that $23 \%$ and $70 \%$ of the respondents are at basic and good ICT levels respectively. Only 7\% indicated being at an excellent level of ICT.

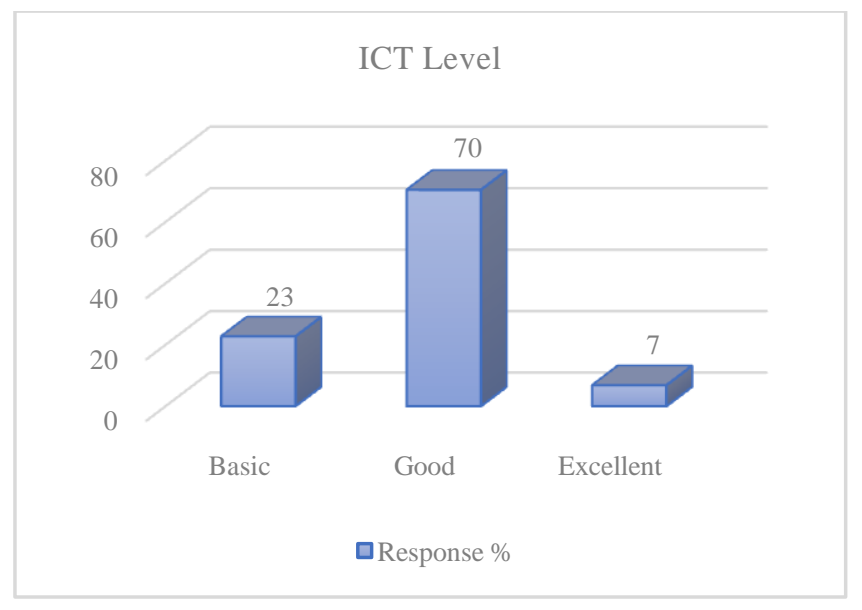

Figure 3: ICT Level
The study conducted to find out the availability of computers at the aircraft maintenance unit revealed the results shown in figure 4. Additionally, the study to find out the knowledge of two basic Microsoft database tools of personnel revealed the results shown in figure 5 .

Is your office equipped with a computer?

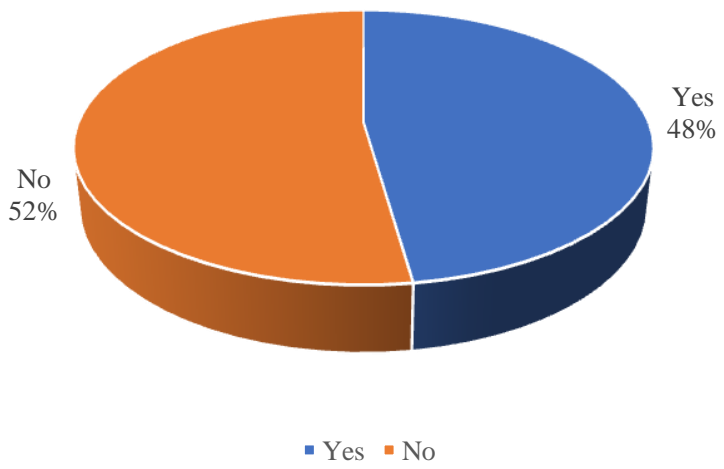

Figure 4: Availability of Computers

Do you have any basic knowledge of the following Microsoft database tools?

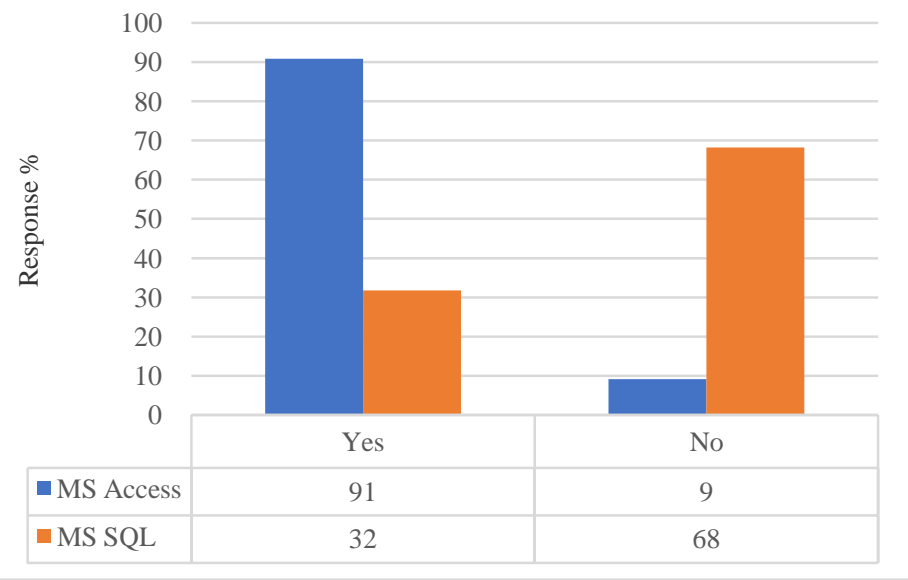

Figure 5: Database Tools Knowledge

\section{Database Development}

Content analysis was done of aircraft maintenance regulations and forms to derive elements necessary for aircraft maintenance that would define the attributes of an electronic database. Three elements of relevant information for aircraft maintenance were identified, namely aircraft information, personnel information and spares, material and equipment information. The database layout was based on these three elements, which were further expanded to systematically divide the required information for storage as summarised in table 5 .

Microsoft Access was used to develop the database because it is one of the tools with which personnel are familiar. 
Additionally, it is an easy tool, user-friendly and can be used together with other Microsoft packages like Word and Excel.

Incremental database modelling was adopted. The three main elements determined the specific entities to use in the database model. The entity fields as illustrated in the Entity Relationship Diagram (ERD) in figure 6 include:

- The aircraft information table that contains fields of relevant information on the aircraft maintained by the unit. The fields include aircraft number, aircraft type, aircraft manufacturer, date of manufacture, manufacturer's ID and serial number, configuration, carrying capacity and aircraft gross weight and the date when weighed. The other fields are for other specifications such as the maximum takeoff weight, cruise speed, climb rate, maximum fuel capacity, endurance, oils, total flying hours, total landings, the engines serial numbers and a column for document attachment.

- Records of the engine type, manufacturer, part number, serial number, power, cycles, speed, total engine hours and recommended inspection period or cycles be for all aircraft engines installed are stored in the engines information table.

- The 'Fixed Wing A' parts catalogue table stores information for all components and part numbers for the aircraft type. This table has fields such as part number, serial number, units per assembly and spares inventory.

- The forms archive table fields include form description, Form ID and the attachments attribute, meaning that forms can be stored in any form.

- The ground support equipment table contains stores support equipment names and numbers, manufacturer, specifications, status, station, servicing date, manual attachments and additional information attributes.

- The due dates and flying hours or total landings of the scheduled maintenance of the aircraft will be stored in the inspection schedules table.

- Maintenance personnel on leave are recorded in the leave table that will shows the start and end date of the leave as well as the trade and appointment of the personnel.

- All personnel approved to access the database will be assigned usernames and issued with passwords. These details will be stored in the users table.

- The various types of oils and lubricants used on each aircraft type are recorded in the oils and lubricants table. The fields in this table include aircraft, engine type, fuel type, maximum fuel capacity, gearbox oil type and maximum capacity, hydraulic fluid type and maximum capacity. The inventory are also be recorded in the table that will the military description numbers.
- Records of out of phase components are recorded in the out of phase table. Fields in this table are aircraft number, component, part number and the flying hours the phased maintenance falls due.

- All maintenance personnel details are recorded in one table that has service number, names, trade, academic qualifications, aircraft conversion, appointment, date of birth, date of enlistment, date of last promotion, NRC number, contact number and marital status and contact details. The training and exams information are stored in a separate table.

- All aircraft components in red ink, the part numbers, when entry was made, the trade involved and spare demand status are compiled in the red ink table.

- The manufacturer service bulletins issued from time to time are in the service bulletins table. The fields in this table are bulletin description, effective date, compliance category and the implementation remarks.

- First line and second line tables were created to store maintenance information such state of the aircraft, as hours flown in the previous 24 hours, hours to next inspection, the type of inspection, fuel state, serviceability forecast of unserviceable aircraft, etc.

The database models representing some of the entities are shown in tables 5 to 8 . Figure 7 shows the database broken down into subfunctions. Figure 8 shows flowchart for the database login operation. Additionally, figures 9 and 10 illustrate the current process of maintenance inspection cards and aircraft state reports generation and distribution respectively. Also shown in figure 11 is the maintenance process with the developed database.

Table 5: Aircraft Information Table

\begin{tabular}{|c|c|c|c|}
\hline \multicolumn{4}{|c|}{ Entity: Aircraft; Table Name: AircraftT } \\
\hline Fields & Data Type & Constraints & Remarks \\
\hline $\begin{array}{l}\text { Aircraft } \\
\text { Number }\end{array}$ & Short Text & Not Null & $\begin{array}{c}\text { Primary key, No } \\
\text { Duplicates, Size }=10\end{array}$ \\
\hline Aircraft type & Short Text & Not Null & $\begin{array}{l}\text { Duplicates OK, } \\
\text { Size }=100\end{array}$ \\
\hline $\begin{array}{l}\text { Manufacture } \\
\text { Date }\end{array}$ & Date/Time & Not Null & Duplicates OK \\
\hline Manufacturer & Long Text & Not Null & $\begin{array}{l}\text { Duplicates OK, } \\
\text { Size }=100\end{array}$ \\
\hline $\begin{array}{l}\text { Manufacturer } \\
\text { ID }\end{array}$ & Short Text & Not Null & No Duplicates, Size $=25$ \\
\hline Serial No & Short Text & Not Null & No Duplicates, Size $=50$ \\
\hline Configuration & Short Text & Not Null & $\begin{array}{l}\text { Duplicates OK, } \\
\text { Size }=100\end{array}$ \\
\hline Total Hrs & Number & Not Null & $\begin{array}{c}\text { Duplicates OK, } \\
\text { Size=Long Integer }\end{array}$ \\
\hline
\end{tabular}




\begin{tabular}{|c|c|c|c|}
\hline $\begin{array}{l}\text { Carrying } \\
\text { Capacity }\end{array}$ & Short Text & Not Null & $\begin{array}{l}\text { Duplicates OK, } \\
\text { Size }=100\end{array}$ \\
\hline Gross Weight & Number & Not Null & $\begin{array}{c}\text { Duplicates OK, } \\
\text { Size=Long Integer }\end{array}$ \\
\hline Weighed on & Date/Time & Not Null & Duplicates OK \\
\hline $\begin{array}{c}\text { Max Take Off } \\
\text { Weight }\end{array}$ & Number & Not Null & $\begin{array}{c}\text { Duplicates OK, } \\
\text { Size }=100\end{array}$ \\
\hline Cruise Speed & Number & Not Null & $\begin{array}{c}\text { Duplicates OK, } \\
\text { Size=Long Integer }\end{array}$ \\
\hline Climb Rate & Number & Not Null & $\begin{array}{c}\text { Duplicates OK, } \\
\text { Size=Long Integer }\end{array}$ \\
\hline Endurance & Number & Not Null & $\begin{array}{c}\text { Duplicates OK, } \\
\text { Size=Long Integer }\end{array}$ \\
\hline Fuel Type & Short Text & Not Null & $\begin{array}{l}\text { Duplicates OK, } \\
\text { Size }=100\end{array}$ \\
\hline $\begin{array}{l}\text { Max Fuel } \\
\text { Capacity }\end{array}$ & Number & Not Null & $\begin{array}{l}\text { Duplicates OK, } \\
\text { Size=Long Integer }\end{array}$ \\
\hline Gearbox Oil & Short Text & Not Null & $\begin{array}{c}\text { Foreign Key, Duplicates } \\
\text { OK, Size }=100\end{array}$ \\
\hline $\begin{array}{l}\text { Max Gearbox } \\
\text { capacity }\end{array}$ & Number & Not Null & $\begin{array}{l}\text { Duplicates OK, } \\
\text { Size=Long integer }\end{array}$ \\
\hline $\begin{array}{l}\text { Hydraulic } \\
\text { Fluid Type }\end{array}$ & Short Text & Not Null & $\begin{array}{l}\text { Duplicates OK, } \\
\text { Size }=100\end{array}$ \\
\hline $\begin{array}{c}\text { Max } \\
\text { Hydraulic } \\
\text { Fluid Capacity }\end{array}$ & Number & Not Null & $\begin{array}{l}\text { Duplicates OK, } \\
\text { Size=Long Integer }\end{array}$ \\
\hline $\begin{array}{c}\text { Total } \\
\text { Landings }\end{array}$ & Number & Not Null & $\begin{array}{l}\text { Duplicates OK, } \\
\text { Size=Long Integer }\end{array}$ \\
\hline & & & \\
\hline
\end{tabular}

\begin{tabular}{|c|c|c|c|}
\hline DOB & Date/Time & Not Null & Duplicates OK \\
\hline DOE & Date/Time & Not Null & Duplicates OK \\
\hline DOP & Date/Time & Not Null & Duplicates OK \\
\hline NRC No & Number & Not Null & $\begin{array}{c}\text { Duplicates } \\
\text { OK, } \\
\text { Size=Long } \\
\text { Integer }\end{array}$ \\
\hline Marital Status & Short text & Not Null & $\begin{array}{c}\text { Duplicates } \\
\text { OK, Size=10 }\end{array}$ \\
\hline Contact No & Number & Not Null & $\begin{array}{c}\text { Duplicates } \\
\text { OK, } \\
\text { Size=Long } \\
\text { Integer }\end{array}$ \\
\hline Email & Short Text & Null & \begin{tabular}{c} 
Size=100 \\
\hline
\end{tabular}
\end{tabular}

Table 7: Users Information Table

\begin{tabular}{|c|c|c|c|}
\hline \multicolumn{4}{|c|}{ Entity: Personnel ; Table Name: UsersT } \\
\hline Fields & Data Type & Constraints & Remarks \\
\hline UserName & Short Text & Not Null & $\begin{array}{c}\text { Primary key, No } \\
\text { Duplicates, } \\
\text { Size }=50\end{array}$ \\
\hline $\begin{array}{l}\text { Service } \\
\text { Number }\end{array}$ & Number & Not Null & $\begin{array}{c}\text { Foreign Key, No } \\
\text { Duplicates } \\
\text { Size=Long } \\
\text { Integer }\end{array}$ \\
\hline Password & Short Text & Not Null & Size $=25$ \\
\hline User Type & Short Text & Not Null & $\begin{array}{c}\text { Duplicates OK, } \\
\text { Size }=10\end{array}$ \\
\hline
\end{tabular}

Table 6: Personnel Information Table

\begin{tabular}{|c|c|c|c|}
\hline \multicolumn{3}{|c|}{ Entity: Personnel ; Table Name: PersonnelT } \\
\hline Fields & Data Type & Constraints & Remarks \\
\hline Service Number & Number & Not Null & $\begin{array}{c}\text { Primary key, } \\
\text { Duplicates, } \\
\text { Size=Long } \\
\text { Integer }\end{array}$ \\
\hline Full Name & Short Text & Not Null & $\begin{array}{c}\text { Duplicates } \\
\text { OK, Size=100 }\end{array}$ \\
\hline Trade & Short Text & Not Null & $\begin{array}{c}\text { Duplicates } \\
\text { OK, Size=100 }\end{array}$ \\
\hline $\begin{array}{c}\text { Academic } \\
\text { Qualification }\end{array}$ & Short Text & Not Null & $\begin{array}{c}\text { Duplicates } \\
\text { OK, Size=200 }\end{array}$ \\
\hline $\begin{array}{c}\text { Aircraft } \\
\text { Conversion }\end{array}$ & Short Text & Not Null & $\begin{array}{c}\text { Foreign Key, } \\
\text { Duplicates } \\
\text { OK, Size=150 }\end{array}$ \\
\hline Appointment & Short Text & Not Null & $\begin{array}{c}\text { Duplicates } \\
\text { OK, Size=150 }\end{array}$ \\
\hline
\end{tabular}

Table 8: Oils/Lubricants Information Table

Entity: Oils/Lubricants ; Table Name: Oils/LubricantsT

\begin{tabular}{|c|c|c|c|}
\hline \multicolumn{2}{|c|}{ Entity: Oils/Lubricants ; Table Name: Oils/LubricantsT } \\
\hline Fields & Data Type & Constraints & Remarks \\
\hline $\begin{array}{c}\text { Oil/Lubricant } \\
\text { Name }\end{array}$ & Short Text & Not Null & $\begin{array}{c}\text { Primary key, } \\
\text { No Duplicates, } \\
\text { Size=Long } \\
\text { Integer }\end{array}$ \\
\hline Mil-Description & Short Text & Not Null & $\begin{array}{c}\text { Duplicates OK, } \\
\text { Size=25 }\end{array}$ \\
\hline Aircraft Number & Short Text & Not Null & $\begin{array}{c}\text { Foreign Key, } \\
\text { Duplicates OK, } \\
\text { Size-150 } \\
\text { (Multiple value } \\
\text { selection } \\
\text { allowed) }\end{array}$ \\
\hline Inventory & Number & Not Null & $\begin{array}{c}\text { Duplicates OK, } \\
\text { Long Integer }\end{array}$ \\
\hline Demanded & YES/NO & Not Null & \\
\hline
\end{tabular}




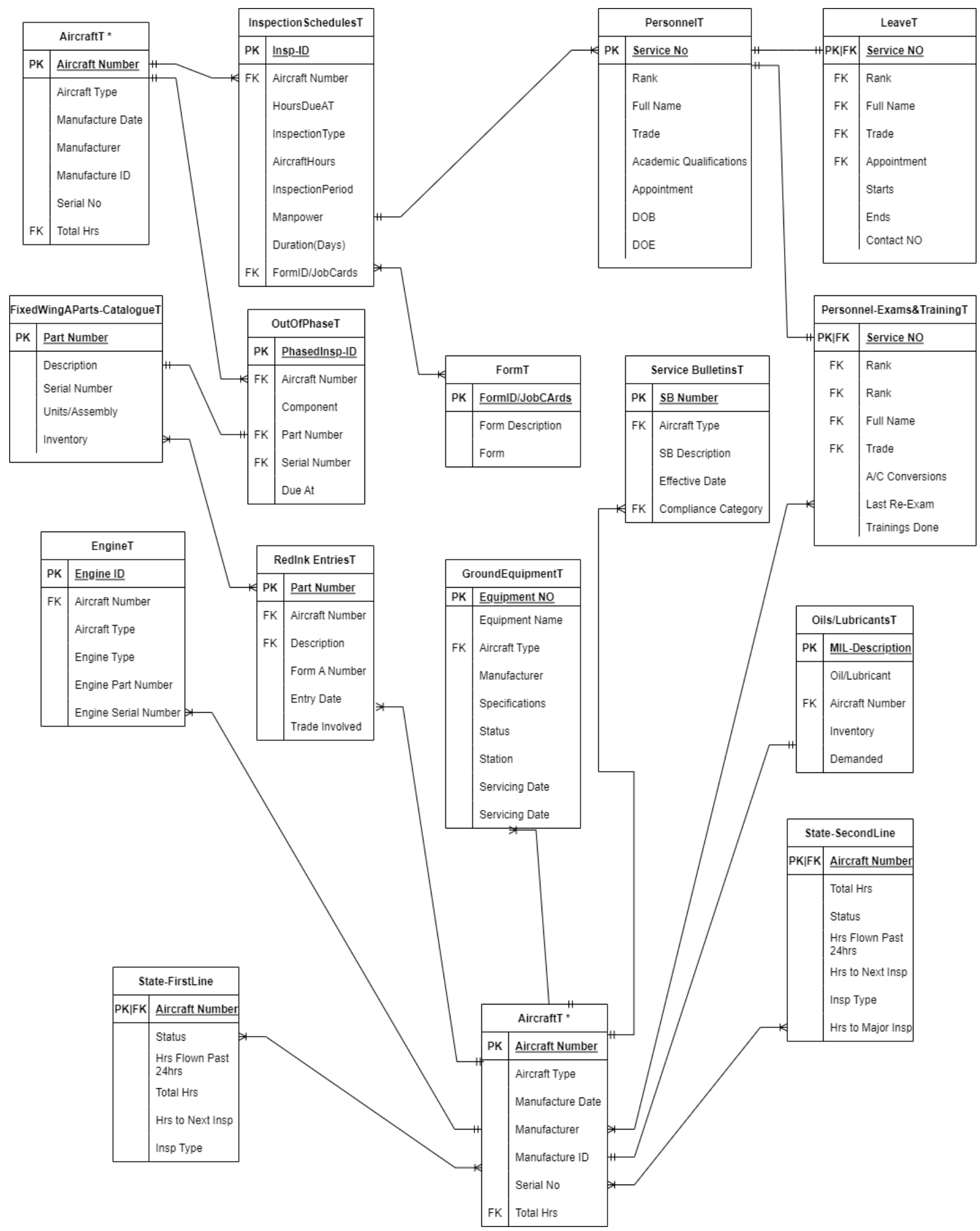

Figure 6: Entity Relationship Diagram (ERD) 


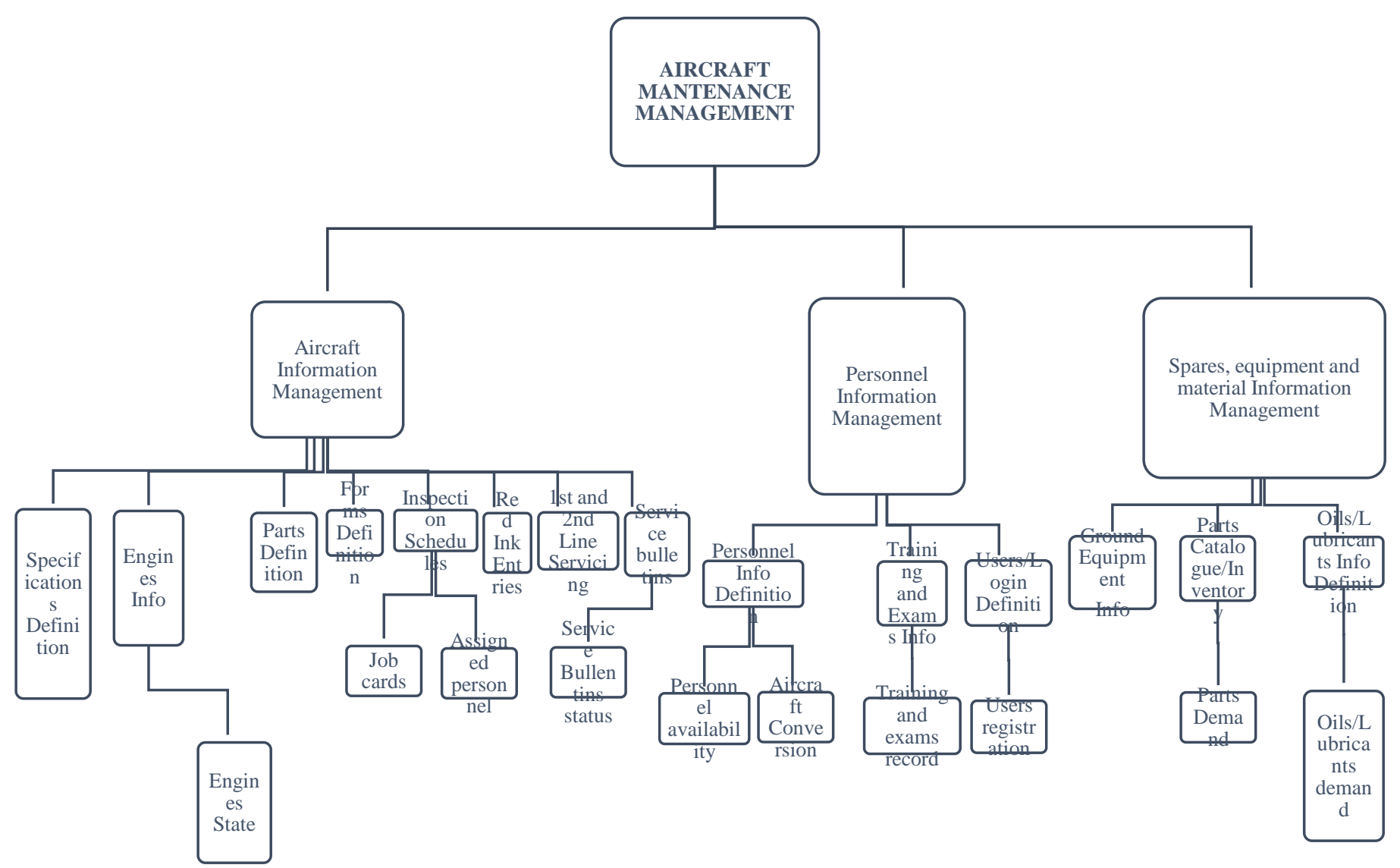

Figure 7: Developed generic system decomposition 


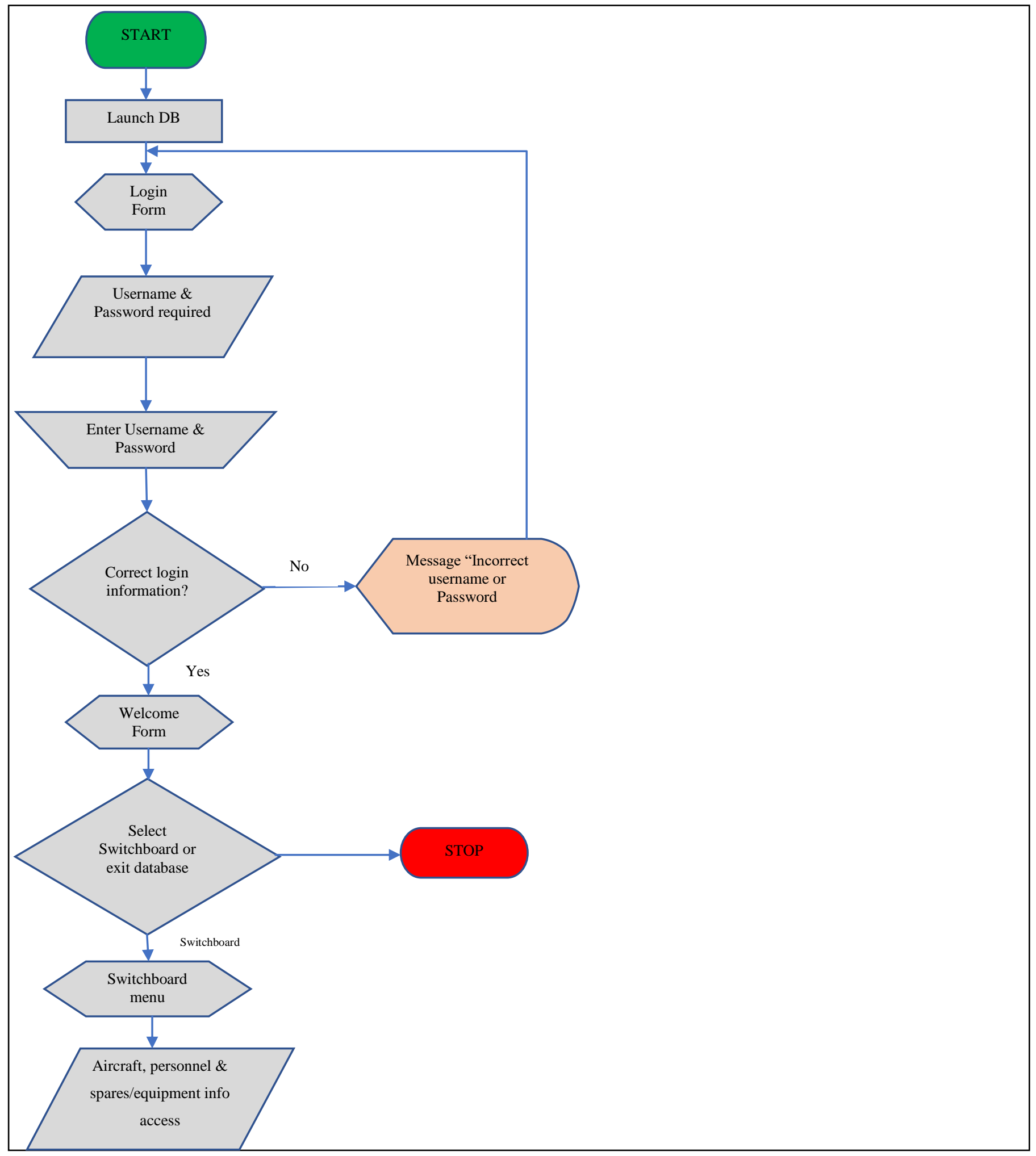

Figure 8: Database login operation 


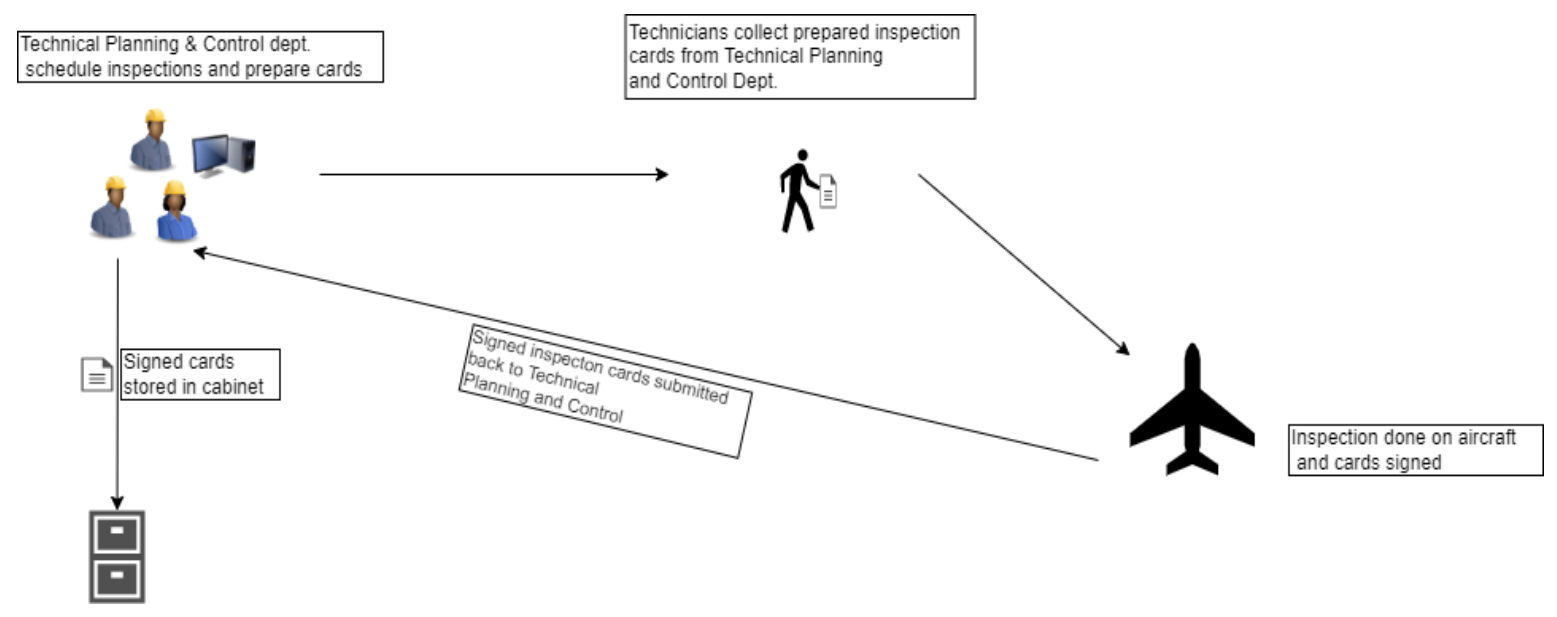

Figure 9: Current inspection card generation and distribution

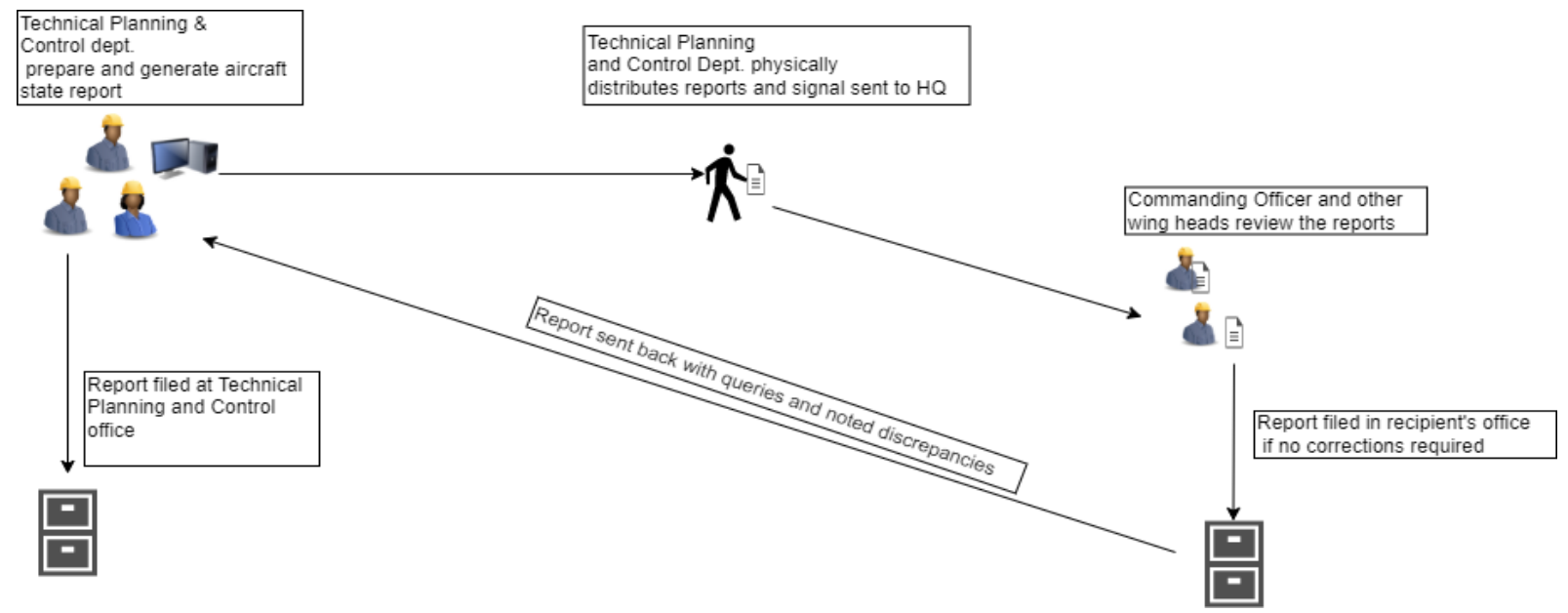

Figure 10: Current aircraft state reports generation and distribution

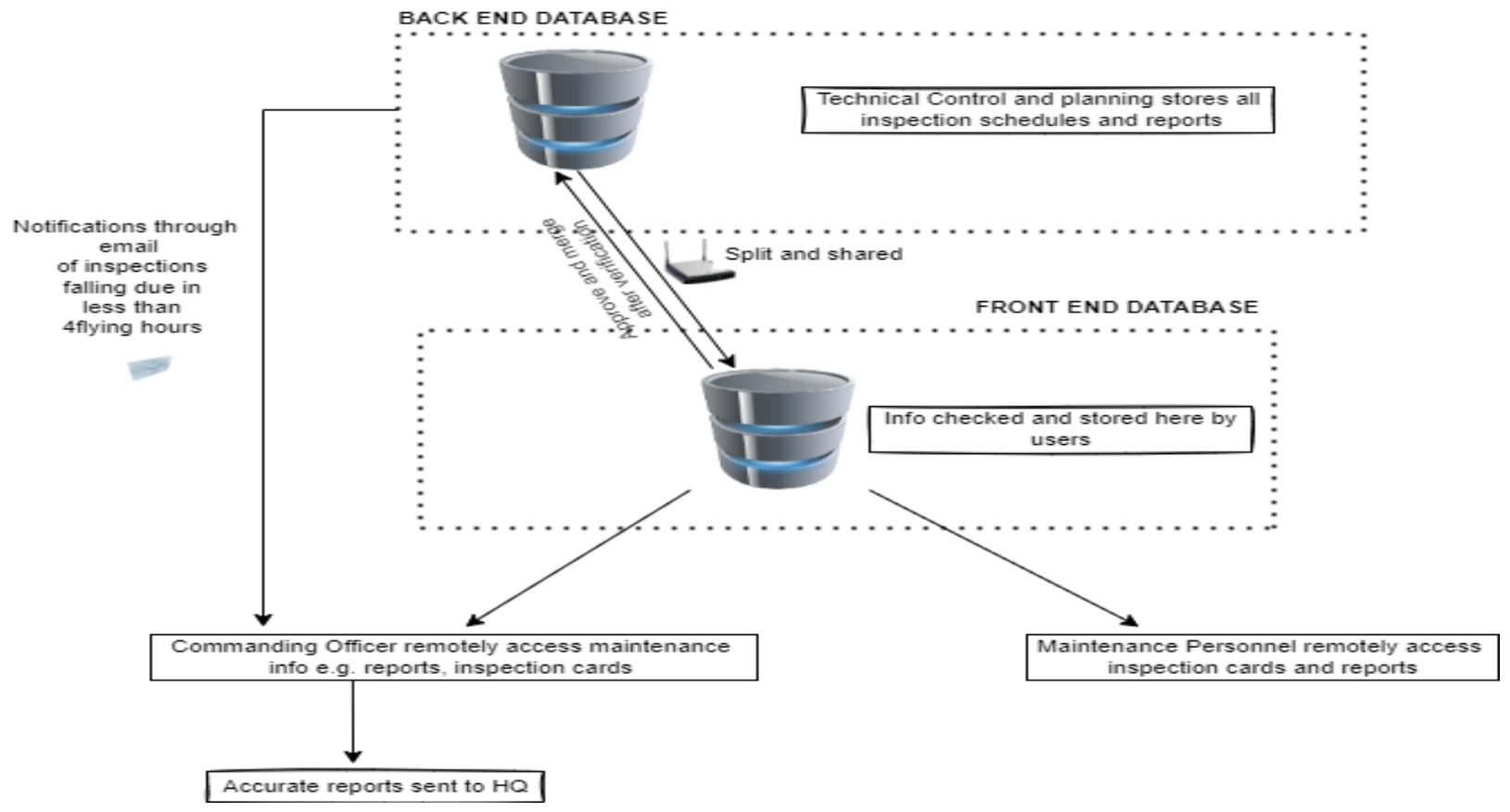

Figure 11: Maintenance process with the developed database. 


\section{E. Implementation and Output Sample}

The developed database was populated with synthetic data to test the function attributes. As shown in the login operation in figure 12 , launching the database firstly leads the user to the login page, which requires input of a username and password assigned by administrators. The page appears as shown in figure 12 below.

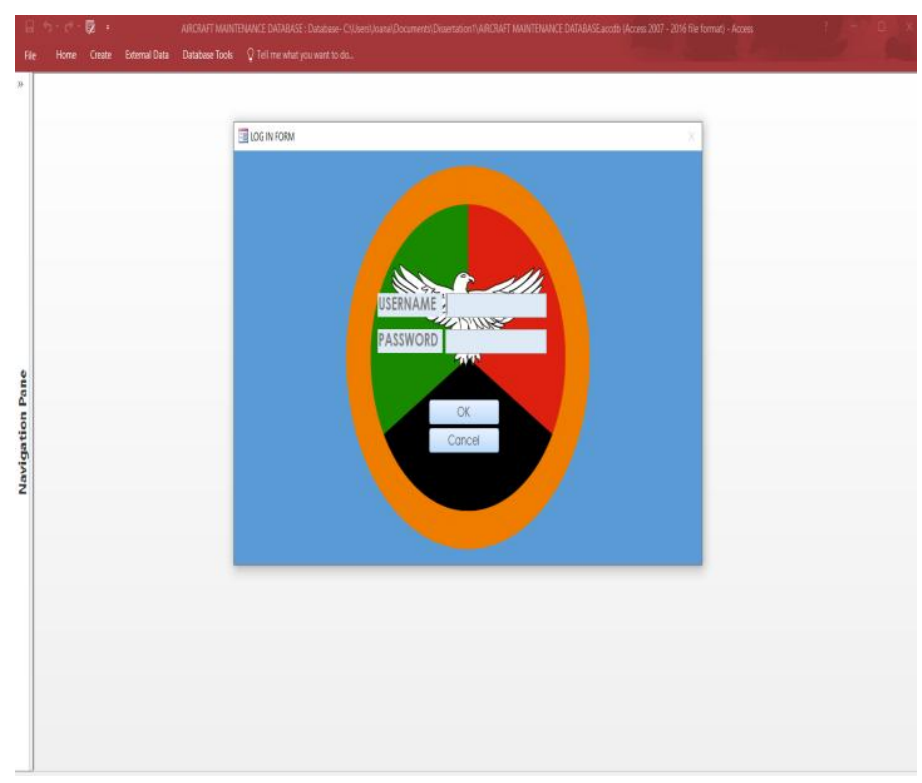

Figure 12: Database login screen

Correct input of username and password opens the welcome screen shown in figure 13.

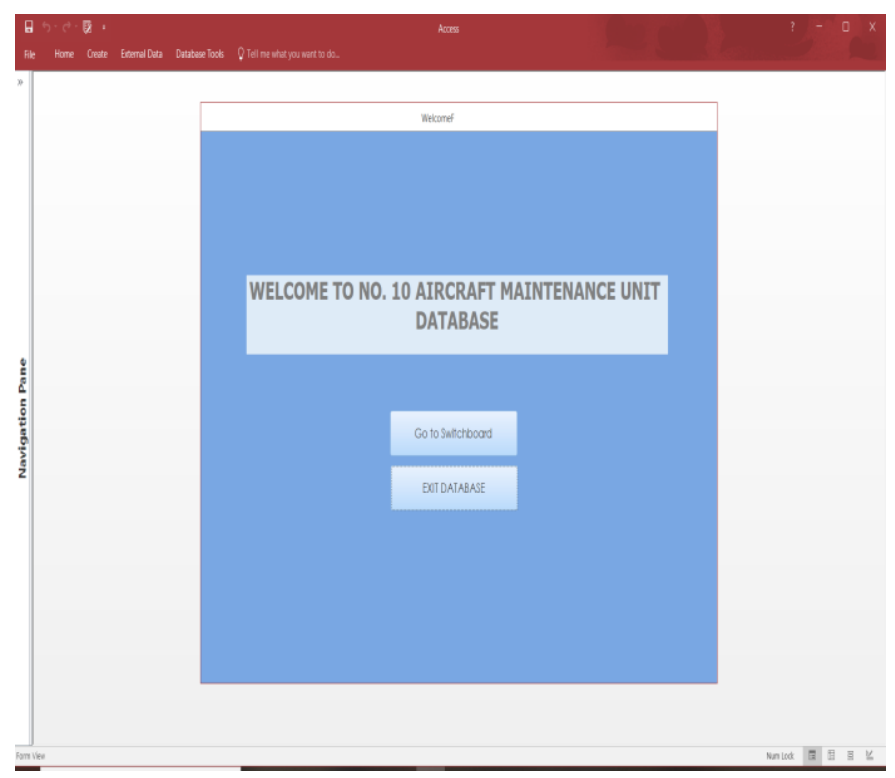

Figure 13: Database welcome screen

The user can then select to open the switchboard or exit the database. Selection of the switchboard redirects the user to options of navigating through the elements of aircraft, personnel, spares, material and other information as shown in figure 14.

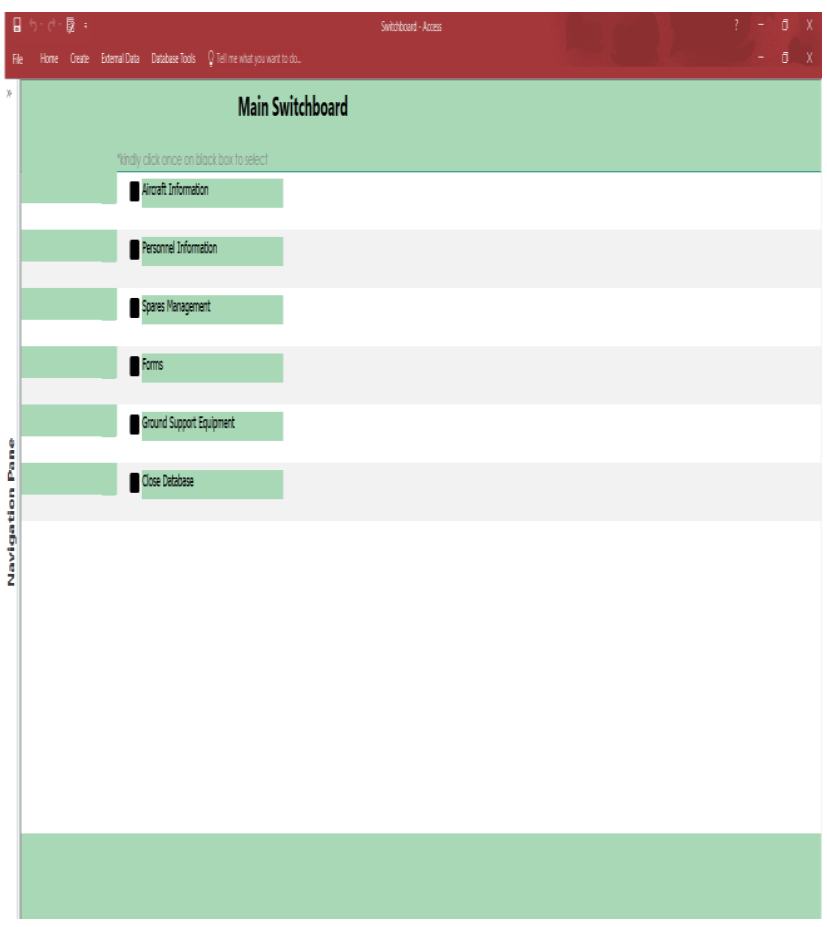

Figure 14: Main switchboard

A further selection of information on the switchboard such as personnel information directs the user to a switchboard with personnel related information as depicted in figure 15.

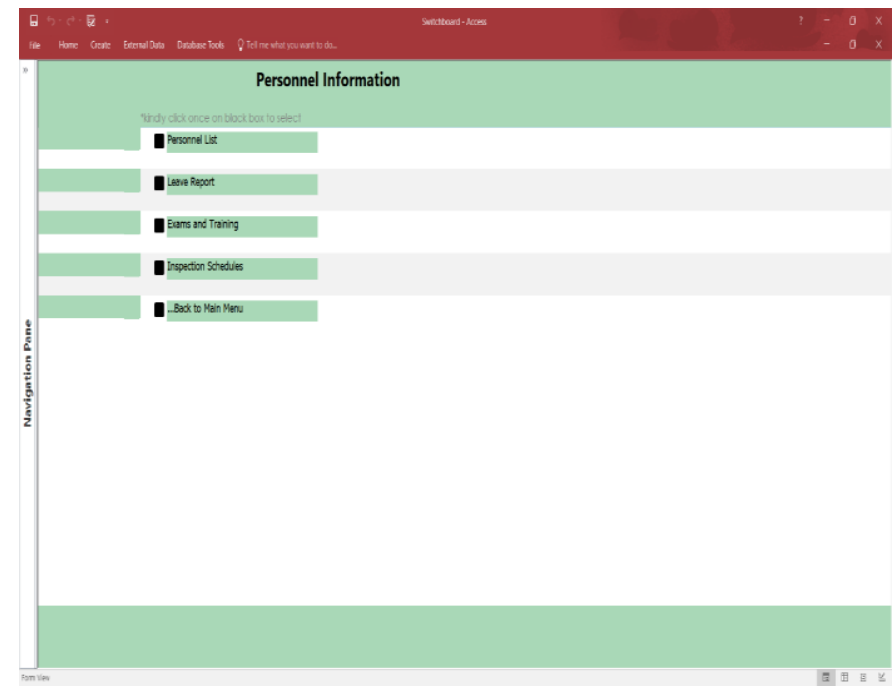

Figure 15: Personnel Information switchboard

An example of output information from this switchboard is the leave report shown in figure 16. Figure 17 shows a screen that pops up after 5 seconds of logging in to notify the user that there are only a few flying hours left to an inspection scheduled. The user has the option to view details of the scheduled maintenance and email the Commanding Officer the reminder. 


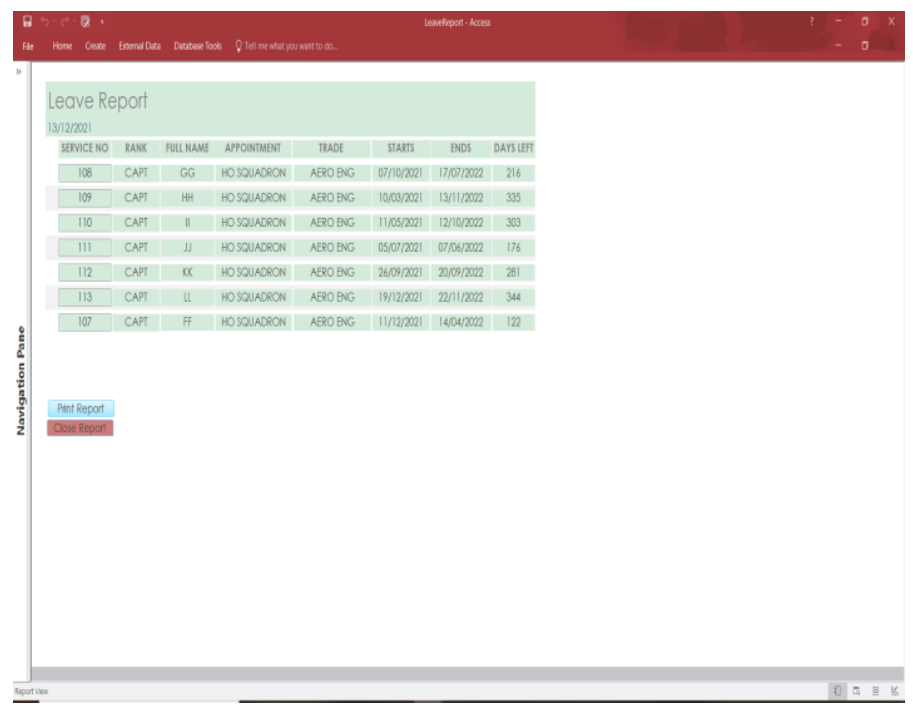

Figure 16: Personnel leave report

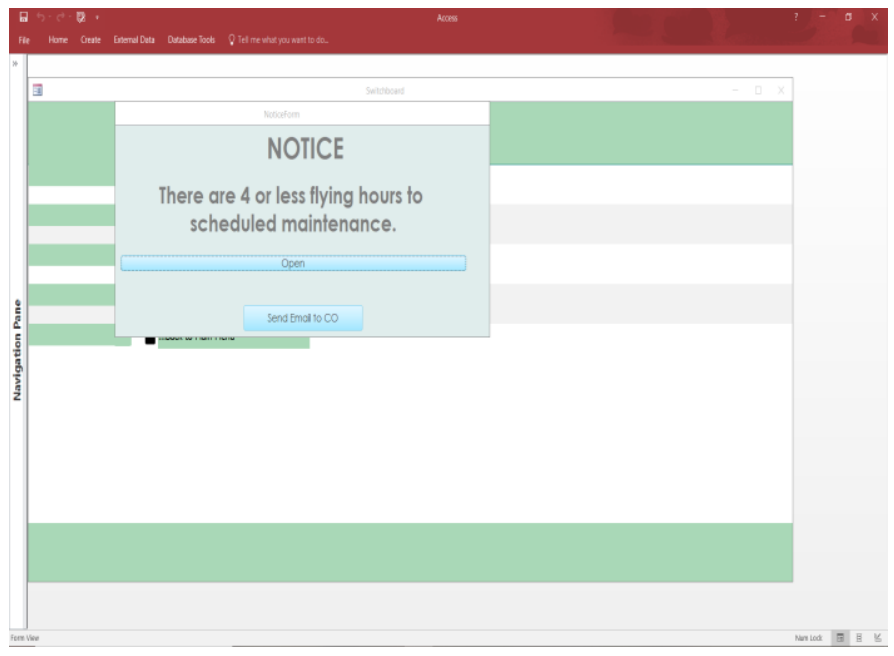

Figure 17: Scheduled Maintenance reminder

\section{DISCUSSION}

An investigation was done to find out the challenges faced in aircraft maintenance information accessibility. As shown in figure $3,77 \%$ of respondents face challenges accessing maintenance information. The challenges revealed are timeconsuming, which was indicated by $53 \%$ of the respondents, while $47 \%$ said documents get misplaced. According to $41 \%$ and $15 \%$ of the respondents, some information is not documented or is incorrect respectively. The database test results showed easy access and improved information search compared to the paper system. In addition, administrators and other users could easily verify information entered remotely from their office computers, ensuring the information on the database is accurate. Findings by Jorgensen \& Fuller (1994; 2006) report significant maintenance performance improvement in the migration from paper to electronic maintenance aid in some USA military maintenance operations. Based on this information, the researcher concluded that ZAF changing from a paper-based maintenance database to an electronic one would similarly present less challenges for personnel.

In order to establish the ICT knowledge level of the maintenance personnel, the researcher carried out a study in this vain. The results showed that $23 \%$ and $70 \%$ of the respondents are at basic and good ICT levels respectively, with only $7 \%$ at an excellent level. Furthermore, the study to find out the availability of computers at the aircraft maintenance unit revealed that $52 \%$ of respondents do not have computers in their offices and only $48 \%$ have their offices equipped with a computer. The researcher wished to know with which common database tools the maintenance personnel are conversant. The results show that $91 \%$ of respondents indicated that they have basic knowledge of Microsoft Access while only $32 \%$ indicated having basic knowledge of Microsoft SQL. Based on these results, the researcher was able to conclude that it is unlikely to be difficult to introduce an electronic aircraft maintenance database because most personnel are ICT literate and have basic knowledge of common database tools like Microsoft Access. However, the institution would require more computers for the offices because less than $50 \%$ of personnel do not have computers in their offices.

The database main design requirement was provision of relevant information for aircraft maintenance planning and execution. This requirement was met with the database having basic functions such as adding, editing, deleting and viewing inspection schedules, service bulletins, engines, personnel, spares and equipment information. Logging into the database requires a username and password assigned by the administrator as illustrated in figure 12 . This capability will ensure information security and prevent unauthorised access of restricted information. The administrator will also be able to define privileges and roles for all users, further securing information. Displayed in figure 17 is a notification that appears five seconds after logging in to remind users of any aircraft with less than four flying hours to scheduled maintenance. This will allow personnel to sufficiently plan for all maintenance works falling due. The current process of inspection cards and report generation and distribution shown in figures 9 and 10 is cumbersome, time consuming and resource demanding. The developed database presents an improvement and efficiency in time resource usage as shown in figure 11. The study by Duarte et al (2013) emphasises the need for a maintenance database and why it is necessary to make collections of reliable and consistent data for analysis and planning of equipment use. This shows the significance of the developed database implementation as it would provide reliable information for aircraft maintenance.

To implement, administrators do not necessarily require extensive knowledge of Visual Basics for Applications (VBA) programming to manage the database. Use of the database will only require the users to be familiar with technical requirements of aircraft maintenance and the Microsoft 
Access interface, hence the need for minimal initial training of basic use and maintenance.

\section{CONCLUSION}

The identified challenges associated with the continued use of a paper-based system are that it is time-consuming, misplaced documents and some information is not documented or is incorrectly. The system output results show that the maintenance database developed met the required specifications and would address the challenges faced with the current system by enabling the rapid access of correct aircraft maintenance information and prevention of misplaced documents. The database capabilities can aid, maintenance managers with (1) decision making (2) maintenance planning and execution and (3) spares inventory management.

\section{RECOMMENDATION}

To address the earlier alluded to challenges associated with the current aircraft management information system at ZAF, it is recommended that the developed system is adopted. The adoption process will require creating a data quality control assessment program, acquisition of computers for maintenance personnel, access to a local internet network and minimal training (because personnel are familiar with Microsoft Access) to introduce the database.

\section{REFERENCES}

[1] Backes M., Miwa F., Okajima C., Souza A. \& Tkacz D., 2017. From Paper To Digital Maintenance With Electronic Signature. Sao-Paulo: Embry-Riddle Aeronautical University.

[2] Belcher G.J \& Neisler R.P, 2000. Cost-Benefit Assessment of Interactive Electronic Technical Manuals in Navy Training and Education, Virginia: Logistics Management Institute.

[3] Duartea J.C., Cunha P.F. \& Craveiro J.T, 2013. Maintenance Database. Procedia CIRP, Volume 7, pp. 551-556.
[4] FAA, 2018. Aviation Maintenance Technician HandbookGeneral. Oklahoma City: U.S. Department of Transportation, Federal Aviation Administration, Flight Standards Service.

[5] Garg A \& Deshmukh S.G, 2015. Maintenance management: Literature review and directions. Journal of Quality in Engineering Maintenance, 12(3), pp. 205-238.

[6] Giridharan S., Nivedha A., Vinothini V. Maha V. \& Kumari N.M, 2020. Web Based Computer Maintenance Management System. Journal of Physics: Conference Series, 1717 (2021), pp. 1-7.

[7] doi:10.1088/1742-6596/1717/1/012045

[8] Gouws L. \& Trevelyan J., 2008. Research on Influences on Maintenance Management Effectiveness. Crawley: University of Western Australia.

[9] ICAO, 2021. International Civil Aviation Organisation. [Online] Available at: https://www.icao.int/Pages/default.aspx [Accessed 28 September 2021].

[10] Johnson W.B \& Millians J.T, 2000. Technology Based Solutions for Process Management in Aviation Maintenance, San Diego, California: HFES CONGRESS 2000.

[11] Jorgensen, E.L. \& Fuller J.J., 1993. The Interactive Electronic Technical Manual. s.l., American Society Naval Engineers/Society for Logistics Engineers Conference.

[12] Jorgensen E.L Fuller J.J, 2006. A Web-Based Architecture for Interactive Electronic Technical Manuals (IETMs), West Bethesda,MD: Naval Surface Warfare Center,Carderock Division.

[13] Kiyak E., 2011. The Importance of Preventive Maintenance in terms of Reliability in Aviation Sector. Eskisehir,Turkey: Anadolu University.

[14] Uniting Aviation, ICAO, 2019. Uniting Aviation. [Online] Available at: https://unitingaviation.com/news/capacityefficiency/the-future-of-mro-emerging-technologies-in-aircraftmaintenance/ [Accessed 03/04/2021 APRIL 2021].

[15] Wiksten J. \& Johansson M., 2006. Maintenance and Reliability: With focus on Aircraft Maintenance and Spares Positioning. Lulea, Sweden: Lulea University of Technology.

[16] ZAF AP, 2004. Air Publication 3301, Vol II, Part 1, Section 2, Leaflet 15. Lusaka: Zambia Air Force.

[17] ZCAA, 2021. Zambia Civil Aviation Requirements, Part 5. Lusaka: Republic of Zambia Civil Aviation Authority 